\title{
GAS DISCHARGE VISUALIZATION - HISTORICAL DEVELOPMENTS, RESEARCH DYNAMICS AND INNOVATIVE APPLICATIONS
}

\author{
Denitsa Grozdeva ${ }^{1,2}$, Tsanka Dikova ${ }^{3}$ \\ ${ }^{1}$ Department of Conservative Dental Treatment and Oral Pathology, \\ Faculty of Dental Medicine, Medical University of Varna \\ ${ }^{2}$ University Centre of Eastern Medicine, Medical University of Varna \\ ${ }^{3}$ Department of Dental Material Science and Propaedeutics of Prosthetic Dental Medicine, \\ Faculty of Dental Medicine, Medical University of Varna
}

\begin{abstract}
INTRODUCTION: Gas discharge visualization (GDV) is a method for a complete diagnosis, which is based on natural physical phenomena in human body. Since the invention of GDV, till present, there has been an increasing interest in its application in different areas of life. The most important use of GVD is in medicine. GDV provides the possibility for quantitative measurement of human physical and psychological well-being. It is used in medicine, psychology and sports for diagnosis, prevention and treatment.

AIM: The aim of this article is to summarize and present to the public health research community the historical developments and the dynamics of the scientific interest in GDV application in conventional and alternative medicine, psychology and sports and to introduce current concepts and innovative techniques of GDV-application in alternative medicine.

MATERIALS AND METHODS: We have applied a historical approach and conducted a literature review of the publish works on the application of GDV in medicine, psychology and sports during the last 70 years.

RESULTS: We observed an increase of scientific interest in GDV - application in medicine, alternative medicine, psychology and sports with progression for each decade, from 1950s - till now. GDV is in the focus of a large number of clinical studies in the three dimensions of medicine - prevention, diagnosis and treatment, with culmination of publishing activity in all of the fields during the last year.

CONCLUSION: Although GDV is not well known in Bulgaria, the results of the presented survey are proving the uniqueness of GDV as a device for diagnosis, prevention and monitoring of diseases. The application opportunities or the application itself of this method in conventional and alternative medicine, psychology and sports, are a chance for further developments of personalized healthcare.
\end{abstract}

Keywords: gas discharge visualization, medicine, alternative medicine, psychology, sports

Address for correspondence:

Denitsa Grozdeva

Faculty of Dental Medicine

Medical University of Varna

84 Tzar Osvoboditel Blvd

9000 Varna

e-mail:denitsa.grozdeva@mu-varna.bg

Received: June 20, 2018

Accepted: July 22, 2018

\section{INTRODUCTION}

Gas discharge visualization (GDV) is a method for diagnosis, based on the natural bioelectricity of the human body, which could be measured in state of health or illness. The essence of GDV consists electron flows capturing from the surface of the skin, induced by short voltage pulses. This phenome- 
non is researched and well known in physics and biophysics as "photoelectron emission". The excited particles, emitted and accelerated in the electromagnetic field, occur as electronic avalanches on the surface of the glass electrode causing a "sliding gas discharge". The discharge of molecules causes natural glow due to their excitement in medium with hydrogen. The electronic emission and gas discharge are amplified by short human electrical stimulation, which is completely safe, without causing any pathological changes. The glow is being measured by the GDV method in real time and gives information about the status of body organs and systems (1-3).

The objects of measurement are the fingertips on both hands, similar to fingerprint scanning. The parameters of electrophotonic emission to be quantified are: intensity, fractality and area of the captured image. The visualization of organs and systems is based on the principles of their acupuncture projection. The image, captured from each of the fingertips is automatically divided into several sectors, similar to the iridogram $(4,5)$.

The registration and measurement of photoelectronic emission from human body is due to its thousand times amplification. This makes the application technique possible without any preparations for the object. The imaging of electron and photon extraction consists of two phases. In the initial stage the electrons from the outer tissues are extracted. The second phase includes capturing of the electron flows from the deepest tissues (1).

Researches have determined the main role of central nervous system in the formation of the fluorescent glow surrounding fingertips. They discovered that adenosine triphosphate (ATP) molecules acts as a neurotransmitter in the autonomous neuromuscular structures. In cases of functional balance and normal operation, the ATP exchange and the electron flow are expected to be regular. Therefore, GDV detects the balance and dysfunction of the central and autonomic nervous system (6).

Healthcare is likely to become more tailored to the individual. The holistic approach to health needs to look towards the balance between the dimensions of human personality: physical, social and psychological (7). GDV has been set up for real time measurement of entropy - the balance between health and illness. The method can also detect the impact of different types of stress (chemical, biological, emotional, physical) on personal health status (8). The effect of sympathetic nervous system and psycho-emotional factor on the whole body can be measured without filter. The parasympathetic nervous system affects the general physiological status of all the systems and this process is registered with the use of filter (9-12).

GDV can be applied in many fields of conventional and alternative medicine, psychology and sports for prevention, early diagnosis and monitoring of therapy. We found evidences for the application of GDV in oncology, surgery, allergology, internal medicine, physical medicine and rehabilitation, acupuncture and homeopathy. GDV also helps with the assessment of the impact of the environment on human health status (13-22).

\section{AIM}

The purpose of this paper is to summarize the dynamics of scientific interest in GDV application in medicine, psychology and sports and to present current concepts and techniques in the use of this device in alternative medicine.

\section{MATERIALS AND METHODS}

A literature review of publications in the Google Scholar scientific platform was conducted for the period of 1950-2018 using the main key-words: "gas discharge visualization", and the additional words: "medicine", "psychology", "sport", "alternative medicine”, "prevention”, “diagnosis", "treatment”, "acupuncture", "yoga", and "homeopathy". The software Microsoft Excel was used for data analysis.

\section{RESULTS AND DISCUSSION}

\section{History and development of gas discharge visualization}

The beginning of the development of gas discharge photography is from XVI-XVII centuries when the first publications for electricity and magnetic fields were published. After a number of inventions and series of studies, in the years 1891-1892, D'Arsonval - a French physician suggested a new method of treatment with high frequency electrical currents. The electricity sent to the skin via glass electrodes ignites the gas inside. Mixing of room air 
Table 1. Historical timeline of the application of GVD in medicine in the end of $20^{\text {th }}$ century (23)

Year Fact
1981 Visualization of internal organs of human body by high frequency photography
Early diagnosis of mental disorders by high frequency photography
Observation of the physical processes, visualized by GVD
Development and first use of a visual camera for diagnosis of human internal organs with standards for
normal and pathological images
Development of an original method for medical diagnosis by fingertip imaging, based on the correlation
with internal organs and determination of the state of diseases

The first GVD test device was designed

with the thermal effect of the electrode results in creating ozone. In fact, the electrical stimulation seemed to cause unexpected benefits such as killing bacteria in the surface of the skin. He pioneered the device to deliver this treatment. Some years later, in 1898, electrophotographic images of different objectives were taken via the Narkevich - Yodko method (23).

In 1949 Semyon Kirlian and his wife Valentina Kirlian began a large investigation of the GDV method, adapting it for application in different spheres of every-day life. In the same year S. Kirlian obtained copyrights of the method - Photography and visualization by high frequency currents. During the 1960s twenty studies were carried out focused on the verification of the effectiveness of Kirlian photography in criminalistics. In 1969, S. Kirlian in collaboration with R.S. Stepanov developed a method for express diagnosis of stomach cancer, based on the Kirlian photography. Ten years later, Paulo de Castro Teixeira - a Brazilian homeopathic doctor, used a Kirlian photography device to observe the therapeutic effect of homeopathic medicines on humans. In the 1970s the book "Psychic Discoveries behind the Iron Curtain" was published in the USA. It presents a pseudoscientific explanation of Kirlian effect. That event triggered an increase of the interest to GDV. First conferences of Kirlian effect with a participation of psychologists were held in the years 1972-1973. At the same time the first book describing the application of Kirlian effect in acupuncture was published. At the end of the 1970s, the diagnostics with GDV were successfully validated, after a number of studies of NASA (23).
GDV use in medicine has been developing since 20-th century (Table 1) and especially in the recent years. The visualization of internal organs was performed by Erasov in 1981. After that Mangana and Zachariadi used high frequency visualization for the diagnosis of mental disorders. At the same time Korotkov passed the dissertation called "Observation of the physical processes visualized by GDV of different objects in nature". The first visual camera for diagnosis of human internal organs and standards for normal and pathological images was developed a year later. In the same year Korotkov developed an original method for real time internal diagnosis by fingertip imaging. He designed the first GDV test device in 1996 (23).

\section{Publishing activity}

The fast development and extensive applicability of GDV in medicine, psychology and sports are well presented with the research of literature, including the last 7 decades.

Fig. 1 shows the expanding publication activity during last 70 years on the application of GDV in 4 fields of medicine published during last 70 years. The research found a small number of articles from the first two decades of the whole period, while at the same time this number reaches 2225 for psychology and 3589 for alternative medicine during the last decade. However, there is a tendency toward equal rates of publishing activity in all of the fields in the last twenty years. We found a highest number of articles published in the area of alternative medicine and a lack of publications about the use of GDV in Bulgaria considering the whole period. 


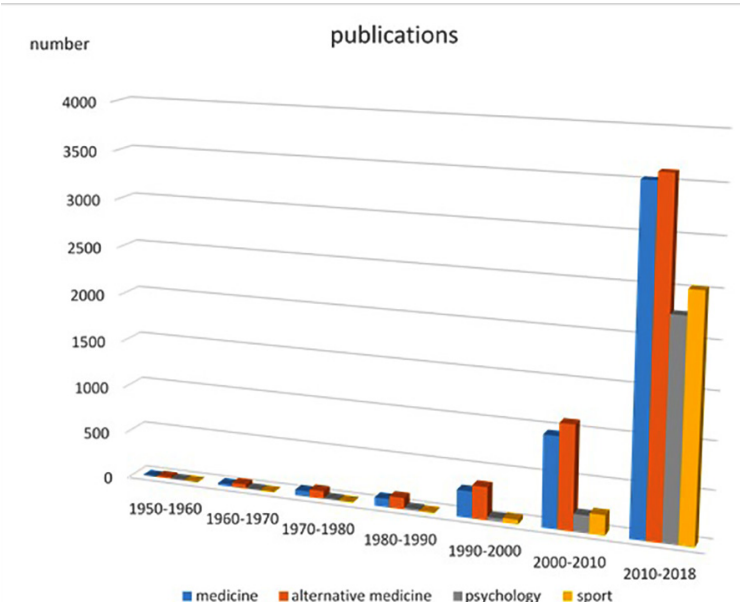

Fig. 1. Application of GVD in medicine, psychology and sports - publication rate for the period 1950-2018

Fig. 2 reports the general amount of papers in medicine, psychology and sports during the last 7 decades and separately over the past year. The publication activity is highest in the medical field. We also found an expanding number of articles in sports and psychology. For the last year the growth rate is calculated as $18.3 \%, 26.8 \%$ and $20.3 \%$ for medicine, psychology and sports, respectively, referring to the period 1950-2018.

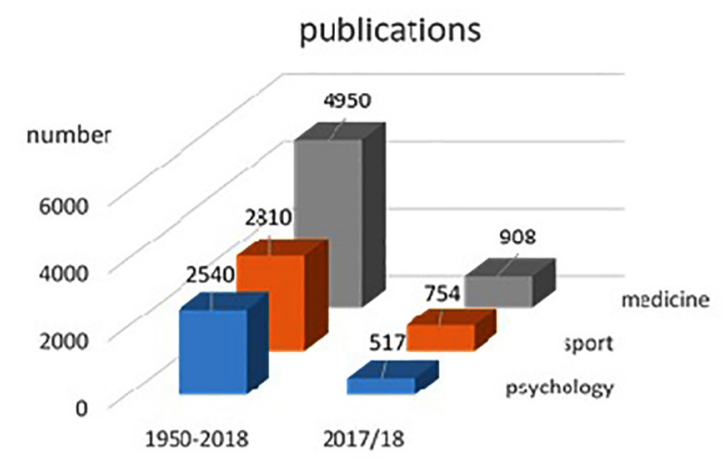

Fig. 2. Number of publications for the last 70 years and over the past year

Fig. 3 presents the publishing activity in prevention, diagnostic and therapy. The results are similar to those reported on Fig. 2 with a tendency towards a growing number of articles published in the period 2017-2018, presented in percentages of the general amount of papers for the last 70 years, as follows: $21.8 \%$ for prevention, $20.3 \%$ for diagnostic and $18.4 \%$ for therapy. These facts confirm the research inter-

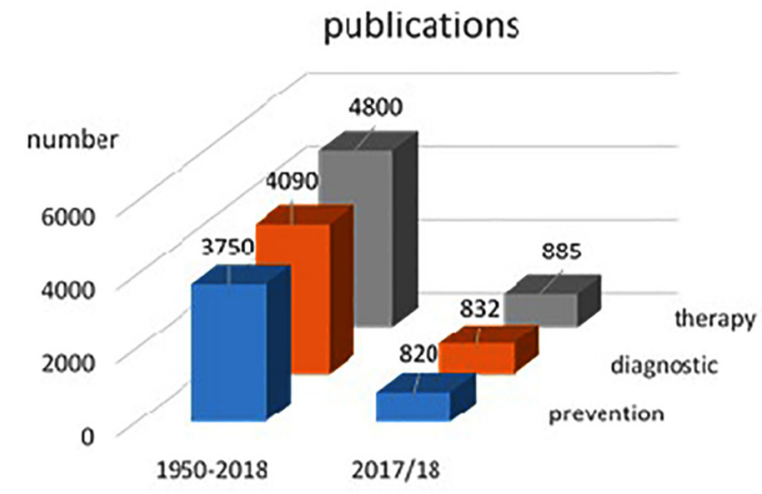

Fig. 3. Number of publications in diagnostic, prevention and therapy fields for the whole period 1950-2018, and separately for 2017-2018

est and could prove the effectiveness of GDV in these fields of medicine.

The number of publications in different spheres of alternative medicine for the last 7 decades is presented on Fig. 4. The first publications on the use of GDV in acupuncture are from the 1980s, followed by application in homeopathy in the 1990s and in yoga - after the 2000s. It is clear that the interest in application of GVD in unconventional medicine is growing exponentially.

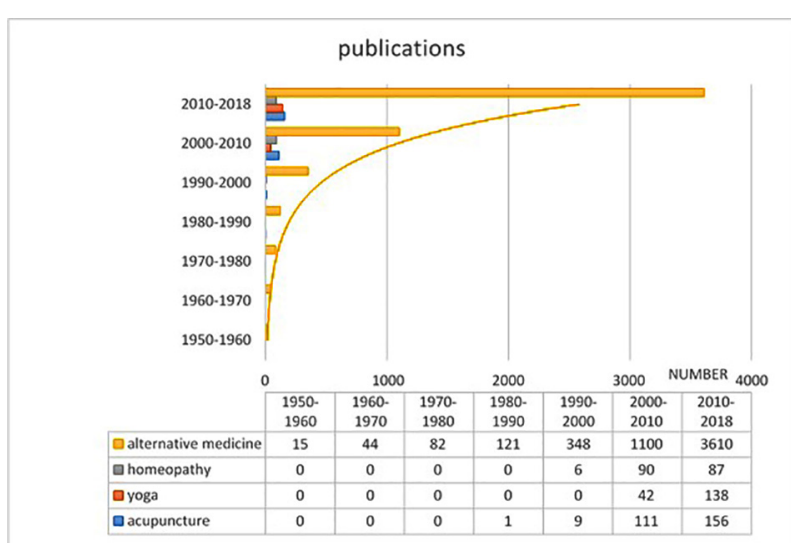

$\varpi$ alternative medicine $\square$ homeopathy $\square$ yoga $\square$ acupuncture — Expon. (alternative medicine)

Fig. 4. Publications in the different fields of alternative medicine for the period 1950-2018

\section{Application of GDV in alternative medicine}

GDV diagnostics have some advantages, such as the easiness of the technique, the possibility for through and real time assessment of the whole individual health status and measurement of the psy- 
cho-emotional state. The impossibility of using GDV in patients with amputated fingers is pointed as the main disadvantage of the method $(2,24)$.

The research of articles published in alternative medicine shows that GDV is mostly used in homeopathy, yoga and acupuncture. The method is applied not only for diagnosis and assessment of the basic human health status but also as a tool for helping to provide an adequate acupuncture, homeopathic or yoga treatment. Additionally GDV is a good device for monitoring the effectiveness of different treatment protocols.

$\diamond$ Homeopathy

GDV is used for assessing the action of some homeopathic medicines. The effect of applying them on healthy people has been studied since the 1970s. Glutathione patch applied on the acupoint CV6 causes positive changes in the physiological state of some organs and systems (liver, kidneys and peripheral nervous system) probably due to the antioxidant activity of Glutathione (25). A similar study was published in 2013. The researchers investigated the effect of Y-age Aeon, another homeopathic medicine on healthy people. They discovered an increased dopamine, glutamate, cysteine and serine production only one day after the start of application. The results confirm the advertised action of Y-age Aeon but no pending changes in mood, motor activity and heart ratio were obtained during the observed period. This fact determines the role of GDV for monitoring and adjusting the duration of the treatment course (26).

$\diamond$ Yoga

We found studies showing the effect of yoga on the entire human body. A significant decrease of catecholamine levels and stress reduction were detected after a one-hour yoga session in healthy people. Different types of yoga practices were investigated for their action on the physiological status of organs and systems, using GDV (27 - 31), with some of the studies involving patients with cancer (32).

\section{$\diamond$ Acupuncture}

The application of GDV in alternative medicine helps for the diagnosis (based on the meridian system) and monitoring the changes caused by acupuncture needles. GVD was used for detecting any differences in energy flows before and after real and sham acupuncture in healthy individuals (33). In a study, conducted in 2016, an in vitro model of acupoints was developed. GDV showed that acupoints act as an amplifier of human stem cells proliferation playing the role of a natural magnetic field. These results suggest that acupuncture works as a regenerative treatment (34).

In recent years the GDV method has become a base of the integrative approach to human health being the first step of attacking diseases and normalizing the photoelectronic flows in the body. This seems to be a reason for including GDV in educational programs of the medical higher education schools worldwide, as timely efforts integrate the methods of alternative healthcare in modern such (35).

\section{CONCLUSION}

Although GDV is not well known in Bulgaria, we presented scientific evidence that it is extremely used worldwide. An expansive research activity on GDV application in medicine, psychology and sports from the beginning of the $20^{\text {th }}$ century till now is was conducted. The results of our research show that over the past year the greatest number of published papers is in alternative medicine (acupuncture, homeopathy, yoga).

GDV has been proven to be an evidence-based diagnostic method, successfully integrating the philosophy of Western and Eastern medicine. It provides a new perspective on the observation of the human body in states of health, illness, physical and psychological stress. This method is a way to integrate conventional and alternative strategies for prevention and treatment in favor of personalizing the approach to human health and disease.

\section{REFERENCES}

1. Kostyuk N, Cole P, Meghanathan N., Isokpehi RD, Cohly HH. Gas dischareg visualization: An imaging and modeling tool for medical biometrics. Int J Biomed Imaging 2011; 2011:196460. doi: 10.1155/2011/196460.

2. Korotkov K, Matravers P, Orlov DV, Williams BO. Application of electrophoton capture (EPC) analysis based on gas discharge visualization technique in medicine: a systematic review. J Altern Complement Med. 2010; 16(1):13-25. doi: 10.1089/ acm.2008.0285. 
3. Srinivasan T. Prana and electrons in health and beyond. Int J Yoga. 2014; 7(1):1-3. doi: 10.4103/0973-6131.123469.

4. Cohy H, Kostyuk N, Isokpehi R, Rajnarayanan R. Bioelectrographic method for preventive health care. First IEEE Annual Bioscience and Biotechnology Conference. 2009.

5. Duerden T. An aura of confusion Part 2: the aided eye - "imaging the aura". Complement Ther Nurs Midwifery. 2004; 10(2):116-23.

6. Krizhanovskyy EV, Korotkina SA, Korotkov KG. Role of the human central nervous system in the formation of the glow of the skin in high intensity electromagnetic field. Ninth annual international congress "Science information spirit, St. Petersburg, Russia. 2005.

7. Mancheva P, Madjova V, Delijski M, Zabunov A. Quality of life assessment methods - Application in general practice. General Medicine. 2006; 8(2):11-14 (In Bulgarian).

8. Korotkov K. Human Energy Field: study with GDV bioelectrography. Fair Lawn, NJ: Backbone Publishing Co. 2002.

9. Sharma B, Hankey A, Nagendra H. Gas discharge visualization characteristics of an Indian diabetes population. Voice of research.2014; (2):28-30.

10. Kushwah K, Srinivasan T, Nagendra H, Ilvarasu J. Effect of yoga based techniques on stress and health indices using electro photonic imaging technique in managers. J Ayurveda Integr Med. 2016:7(2):11923. doi: 10.1016/j.jaim.2015.05.001.

11. Korotkov K, Shelkov O, Shevtsov A, Mohov D, Paoletti S, Mirosnichenko D et al. Stress reduction with osteopathy assessed with GVD electrophotonic imaging: effects of osteopathy treatment. J Altern Complement Med. 2012; 18(3):251-7.

12. Bell I, Lewis DA, Brooks AJ, Lewis SE, Schwarz GE. Gas discharge visualization of ultramolecular doses of homeopathic medicines under blinded, controlled conditions. J Altern Complement Med. 2003; 9(1):25-38. doi: 10.1089/107555303321222928.

13. Vepkhvadze R, Gagua R, Korotkov K, et al. GDV in monitoring of lung cancer condition during surgical treatment. J Georgian Oncology. 2003; 1(4): 60.

14. Alexandrova R, Fedoseev G, Korotkov K, Philippova N, Zayzev S, Magidov M, et al. Analysis of the bioelectrograms of bronchial asthma patients. In: Korotkov K, editor. Measuring Energy Fields: Current Research - Fair Lawn, USA: Back- bone Publishing Co. 2004. p.75-82. Available from: http://www.biowell.com/assets/files/papers/Medicine/2004\%20Alexandrova.pdf.

15. Strukov EU. Opportunities of gas discharge visualization technique in the estimation of functional state of the organism in perioperative period. Available from: http://www.bio-well.com/assets/files/papers/Medicine/2003\%20Strukov_E.pdf.

16. Roberts N, Shealy C, Tiller W. Are There Electrical Devices that can Measure the body's Energy State Change to an Acupuncture Treatment? Part II. The Gas Discharge Visualization (GDV) Device. Available from: http://www.bio-well.com/assets/files/papers/Medicine/2004\%202\%20N\%20Roberts\%20E. pdf.

17. Gagua PO, Gedevanishvili EG, Georgobiani LG, Kapanadze A, Korotkov KG, Korotkina SA, Achmeteli GG, Kriganivski EV. The GDV technique application in oncology. Available from: http:// www.biowell.com/assets/files/papers/Medicine/2004\%20Experimental\%20Study\%20Oncology.pdf.

18. Gimbut VS. Diagnostic possibilities of the modified GDV technique in obstetrics. Available from: http://www.bio-well.com/assets/files/papers/Medicine/2004\%20Gimbut.pdf.

19. Stepanov A, Sviridov L, Korotkina SA, Achmeteli GG, Kriganivski EV. Application of the GVDGraphy technique for the estimation of antigen antibody reaction. Available from:http://www.biowell.com/assets/files/papers/Medicine/2004\%20 Immunology_E.pdf.

20. Yakovleva EG, Korotkov KG, Feodorv ED, Ivanova EV, Plahov RV, Belonosov SS. Engineering Approach to identifying patients with colon tumors on the basis of electrophotonic imaging technique data. The Open Biomedical Engineering Journal. 2016; (10):72-80.

21. Buck KH, Novelli C, Costa FT, Martins GC, Oliveira H, Camargo LB et al. Use of electrobiographic photo on compariosn among breast cancer, healthy sedentary, and healthy runners women. Centro de Pesquisas Avançadas em Qualidade de Vida. 2016; 8(2):1-9.

22. Aleksandrova E, Zarubina TV, Kovelekova MN, Strychkov PV, Yakovleva EG. GDV Analysis of Arterial Hypertension. Available from: http:// www.bio-well.com/assets/files/papers/Medicine/2009\%20Jakovleva.pdf. (Accessed: 16 July 2018). 
23. Shustov MA. History of GDV development. In: Korotkov KG, Shustov MA. Kirlian effect - history and present - St. Petersburg; 2017: p.6-53. (In Russian).

24. Leskowitz E. Energy medicine perspectives on phantom - limb pain. Alternative and complementary therapies. 2009; 15(2). Available from: https://www.liebertpub.com/doi/pdf/10.1089/ act.2009.15210. (Accessed July 24, 2018).

25. Connor MH, Maret K, Eng M. Gas discharge visualization testing of Livewave Glutathione Patches. 2011. Available from: https:/lifewave.com/Content/images/home/science/pdf/Research-2011-DischargeVisualizationTesting.pdf.( Accessed July 23, 2018)

26. Connor M, Eickhoff J. Amino Acid, Nevrotransmitter, GDV and Physiological testing of the LiveWave Y-Age AEON Patch. 2013. Available from: https://www.researchgate.net/publication/281494896_Amino_Acid_Neurotransmitter_GDV_and_Physiological_Testing_of_the LifeWave_Y-Age_AEON_Patches. (Accessed July 23, 2018).

27. Narayanan CR. EPI Reading of Before and After Yoga Session. 2014. Available from: http://www. biowell.com/assets/files/papers/Yoga/2014\%20 Rajan\%20Narayanan_EPI_Yoga\%20Session\%20. PDF. (Accessed July 19, 2018).

28. Sushrutha S, Hegde M, Nagendra HR, Srinivasan TM. Comparative study of Influence of Yajña and Yogāsana on stress level as Measured by Electron Photonic Imaging (EPI) Technique. Int J Sci Res. 2014, 3(8):1402-6.

29. Sushrutha SI, Madappa K, Nagendra HR. Effect of Bhaishajya Maha Yajna on Human Energy Field and Environment. International Journal of Innovative Research in Science \& Engineering. Available from: http://www.biowell.com/assets/files/papers/ Yoga/2015\%20Fire\%20ceremony\%20Sushrutha. pdf. (Accessed July 19.2018).

30. Deo G, Itagi RK, Thaiyar MS, Kuldeep KK. Effect of anapanasati meditation technique through electrophotonic imaging parameters: A pilot study. Int J Yoga. 2015; 8(2):117-21. doi: 10.4103/0973-6131.158474.

31. Kushwah KK, Srinivasan TM, Nagendra NR, Ilavarasu JV. Effect of yoga based techniques on stress and health indices using electro photonic imaging technique in managers. J Ayurveda Integr Med. 2016, 7(2): 119-23. doi: 10.1016/j.jaim.2015.05.001.
32. Jain D, Jain V, Patel M, Kayarker UM, Agarwal M, Joseph A. Yogic perspective on cancer. Available from:http:/www.biowell.com/assets/files/papers/ Yoga/2017\%20Yogic\%20Perspective\%20on\%20 Cancer.pdf.(Accessed July 19, 2018)

33. Nancy R. Roberts N, Shealy CN, Tiller WA. Are There Electrical Devices that can Measure the body's Energy State Change to an Acupuncture Treatment? Part II, The Gas Discharge Visualization (GDV) Device. In Korotkov KG, editor. Measuring Energy Fields: Current Research. Fair Lawn, USA: Backbone Publishing Co; 2004.

34. Ermelyanov, AN, Borisova MV, Kiryanova VV. Model acupuncture point: Bone marrow-derived stromal stem cells are moved by a weak electromagnetic field. Wolrd J Stem Cells. 2016, 8(10): 342-54.

35. Deshpande $\mathrm{P}$, Kowall J. Integrative approach for medical curricula. Available from: http://www.biowell.com/assets/files/papers/Medicine/2017\%20Integrative\%20Approach\%20for\%20Medical\%20Curricula.pdf (Accessed July 17, 2018). 